\title{
Rapid adaptation of the vestibulo-ocular reflex and induced self-motion perception
}

\author{
CLIFTON SCHOR and CAROL WESTALL \\ University of California, School of Optometry, Berkeley, California
}

\begin{abstract}
Directional asymmetries of vestibular induced self-motion perception and the vestibulo-ocular reflex (VOR) were observed in darkness following adaptation to unidirectional movement of a large textured visual field. Following short-term adaptation $(1 \mathrm{~min})$ to visual motion with the body stationary, observers reported that their sensitivity to body rotation in darkness was reduced in the same direction as the previous adapting stimulus and was enhanced in the opposite direction. The duration of this aftereffect was at least six times longer than those of aftereffects of circular vection when the observer remained stationary in darkness. The opposite distortion of self-motion perception was observed after long-term visual adaptation (15 min) in which sensitivity to body rotation in darkness was reduced in a direction opposite to the adapting drum rotation. Changes in self-motion perception resulted from interactions between visually induced illusions of self-motion (vection) and habituation of vestibular induced self-motion perception. The short- and long-term aftereffects were both accompanied by reductions of slow-phase gain of the VOR when the body rotated in the same direction in which self-motion perception was reduced. If the observer was stationary in darkness, there was also a motion-induced afternystagmus. Following short-term adaptation, afternystagmus was too brief to interact with the modified VOR; following long-term adaptation, however, a sustained inverted afternystagmus could have summed linearly with the vestibular responses and caused an apparent modification of the VOR. A pure visual stimulus is believed to produce rapid modification of the VOR so that it can anticipate head movements and maintain stability of the retinal image while the observer tracks a moving visual field.
\end{abstract}

Both the visual and vestibular systems provide a major influence on the perception of body movement (selfmotion) as well as on fixational eye movements that maintain a stabilized retinal image as the body moves (Brandt, Dichgans, \& Koenig, 1973; Dichgans \& Brandt, 1972; Fischer \& Kornmuller, 1930; Mach, cited in Henn, Cohen, \& Young, 1980; Schor, Lakshminarayanan, \& Narayan, 1984; Young, Dichgans, Murphy, \& Brandt, 1973). Vestibular stimulation during body rotation evokes the vestibulo-ocular reflex (VOR) and self-motion perception. Visual stimulation results in the optokinetic reflex as well as self-motion perception, which is demonstrated by the illusion of self-motion (circular vection) produced while a stationary observer views a large moving field (Brandt, Dichgans, \& Buchele, 1974). Prolonged stimulation of vision with optical flow results in adaptation of both the perceptual and motor responses. Adaptation to optical flow is demonstrated by the continuation of circular vection (Brandt et al., 1974) and optokinetic nystagmus (afternystagmus) (Brandt et al., 1974; Koenig \& Dichgans, 1981; Schor \& Westall, 1984) in darkness. These sensory and motor aftereffects become inverted after long-term ( $>4 \mathrm{~min}$ ) adaptation to motion (Brandt

This work was supported by National Eye Institute Grant EYO 3532 and National Institutes of Health Core Grant 1-445420-32011. Requests for reprints should be directed to C. Schor, School of Optometry, University of California, Berkeley, CA 94720. et al., 1974). In this study, we examined the interaction between vestibular stimulation with these perceptual and motor aftereffects of adaptation to optical flow in order to investigate possible interactions between visual and vestibular stimuli. We also investigated visual-vestibular interaction by comparing aftereffects resulting from adaptation to purely visual motion and combined visual-vestibular stimulation.

Previous studies of self-motion perception had demonstrated marked reductions of vestibular induced selfmotion perception when the body was rotated in the direction opposite to that of ongoing circular vection stimulated by a moving visual field (Young et al., 1973). Motor studies had shown that the slow-phase gain of the VOR became modified in response to conflicting visual and vestibular stimuli (Miles \& Eighmy, 1980). For example, visual-vestibular conflicts produced by mirror-reversed images (Gonshor \& Melvill Jones, 1976), magnifying spectacles (Collewijn, Martins, \& Steinman, 1983; Miles \& Eighmy, 1980; Miles \& Lisberger, 1981), or field rotation about a moving observer (Young \& Henn, 1974, 1976; Koenig \& Dichgans, 1981; Westall \& Schor, 1985) can produce rapid changes in the slow-phase gain of the VOR in 1-2 min (Collewijn et al., 1983; Westall \& Schor, 1985). Purely visual motion also causes changes in the slow-phase gain of the VOR measured in darkness (Yee \& Baloh, 1986; Young et al., 1973). In this study, we made a direct comparison of the amplitude and dura- 
tion of these perceptual and motor aftereffects following adaptation to visual motion alone or to combined visualvestibular stimulation to determine how these stimuli might interact with one another.

\section{METHOD}

\section{Experimental Procedures}

Three categories of experiments were conducted. In the first category, baseline measures of vestibular induced self-motion perception as well as measures of fixation drifts and the VOR were obtained in darkness. In the second category, the aftereffects of short-term stimulation $(1 \mathrm{~min})$ with purely visual motion were compared with aftereffects of combined visual-vestibular stimulation. Aftereffects obtained in darkness from these two stimuli are described for circular vection, vestibular induced self-motion perception, fixational drifts, and the slow-phase velocity of the VOR. In the third category, sensory and motor aftereffects of long-term visual stimulation $(15 \mathrm{~min})$ with optical flow were examined for the sensory and motor qualities listed in Category 2. Due to the variety of experiments, specific procedures will be presented for each experiment in the results section.

\section{Subjects}

The two authors served as subjects in all three categories of experiments. Two additional subjects, who were unaware of the hypothesis being tested, participated in the first two categories of experiments. All but 1 subject (C.W.) had normal visual acuity in each eye and normal binocular alignment. C.W. had reduced visual acuity in her right eye (20/50) as a result of amblyopia. However, this subject had normal binocular eye alignment. The order of tests, described above, was the same for all subjects, but only one stimulus category and duration were presented on a given day. Each condition was presented to each subject twice, and each trial consisted of 16 observations (motor or sensory) taken once every $4 \mathrm{sec}$ for a 64 -sec period. Between trials, subjects rested for 3 min while looking at stationary objects to discharge any remaining aftereffects (Lisberger, Miles, Optican, \& Eighmy, 1981).

\section{Eye-Movement Recording}

Eye movements were monitored with a limbal reflection infrared sensing device (Gulf Western SGVH/2) and recorded on a strip chart recorder. The eye-movement monitor was calibrated by fitting a regression equation to the voltage changes plotted as a function of step changes in eye position ranging from $0.5^{\circ}$ to $10^{\circ}$. Without the subject in the recording apparatus, sensitivity of the system was indicated by the standard deviation of noise level, which corresponded to $6^{\prime}$ of arc eye rotation. With the subject in the apparatus, the standard deviation of the noise level increased to $10^{\prime}$ of arc during attempted steady fixation of a stationary target. This threshold provided an estimate of the sensitivity of the recording system.

\section{Stimulus}

With head restrained by a headrest, the subject sat on a chair inside a vertical 4 -ft-diam translucent optokinetic drum. The chair was either stationary or mechanically oscillated $36^{\circ}$ (peak to peak) at three frequencies $(0.125,0.25$, and $0.45 \mathrm{~Hz})$ about a vertical axis. In prior studies (Schor \& Westall, 1984), we had found these stimulus frequencies to effectively reveal VOR slow-phase imbalance between the leftward and rightward directions. During chair oscillation, the angular velocity of the drum could be matched to that of the chair in one direction of rotation. Random black dots $\left(2^{\circ}\right.$ to $10^{\circ}$ ) lined the surface of the white drum. The room lights were turned on for viewing of the moving visual stimulus; aftereffects were measured in total darkness. During either visual or visual- plus-vestibular adaptation periods, the observers fixated a headreferenced spot in order to suppress optokinetic nystagmus.

\section{RESULTS}

Baseline Measures

\section{Vestibular Induced Self-Motion}

During sinusoidal body rotation $\left(0.25 \mathrm{~Hz}, 36^{\circ}\right.$ peak to peak) in darkness, subjects estimated the magnitude of perceived self-motion as a ratio of rightward over leftward $(R / L)$ perceived velocity. During this procedure, the subjects were instructed to fixate an imaginary stationary earth-referenced target. Estimates were reported every $4 \mathrm{sec}$ for 16 stimulus cycles in two $64 \mathrm{sec}$ trials. Table 1 displays baseline measures of $R / L$ ratios of vestibular induced self-motion perception. Ratios of 1.0 correspond to balanced sensations of rightward and leftward motion, and lower ratios indicate that there was greater sensitivity to leftward than to rightward motion. Mean baseline ratios varied among observers from 0.5 to 1.0 .

\section{Fixational Drifts in Darkness}

When the lights were turned out, the subjects were instructed to look at an imaginary earth-referenced point in the direction that a visible stationary target had previously occupied. Eye movements were measured for $32 \mathrm{sec}$ in darkness. Their mean velocity was analyzed manually by sampling the slow-phase drift velocity and direction at $0.5-\mathrm{sec}$ intervals. Figure 1 provides an example of a rightward fixation-drift bias in darkness of $0.32 \mathrm{deg} / \mathrm{sec}$. Table 2 presents mean dark fixation-drift velocities of the 4 subjects during the first two 16-sec periods of the recording.

\section{Horizontal Symmetry of the VOR}

Horizontal components of eye movements in darkness were measured during the stimulus condition described in the preceding section on vestibular induced self-motion perception. An example of the resulting vestibulo-ocular reflex in darkness is shown in Figure 1. A normal rightward bias of slow-phase velocity is demonstrated by the cumulative slow-phase plot of the VOR. The continuous

Table 1

Modified Vestibular Induced Self-Motion Perception

\begin{tabular}{lccc}
\hline & & \multicolumn{2}{c}{ Adaptation Condition } \\
\cline { 3 - 4 } Subject & Baseline & Visual & Visual-Vestibular \\
\hline A.B. & 0.8 & 1.75 & 1.60 \\
B.B. & 1.0 & 1.85 & 2.00 \\
C.W. & 0.5 & 1.60 & 1.50 \\
C.S. & 0.8 & 2.00 & 2.15 \\
\hline
\end{tabular}

Note-Estimates of right/left velocity of self-motion perception during $0.25-\mathrm{Hz}$ body oscillation in darkness are listed for baseline conditions and for short-term (1 min) adaptation conditions of pure visual stimulation and of combined visual-vestibular stimulation. Values equal the means of estimates reported during the first eight stimulus cycles or $32 \mathrm{sec}$ in darkness. Both adaptation conditions resulted in similar strong rightward biases of vestibular induced self-motion perception relative to baseline measures. 
A. B.
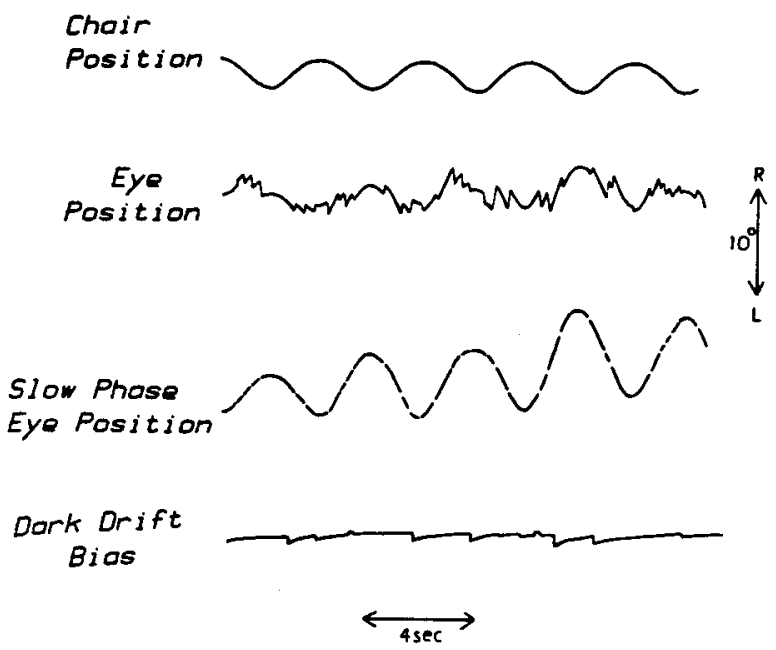

Figure 1. The baseline VOR, stimulated in darkness by a $0.25-$ Hz sinusoidal rotation, is shown along with its cumulative slow-phase plot. The VOR has a rightward slow-phase bias of $0.47 \mathrm{deg} / \mathrm{sec}$ that is in the same direction as for a $0.32-\mathrm{deg} / \mathrm{sec}$ drift bias of fixational eye movements also measured in darkness.

slow-phase components of the VOR were derived manually by subtracting the saccadic movements from the original recording of the VOR. The peak velocities of the left and right slow-phase eye movements were measured as the slopes between the position peaks, and the respective means were calculated. The imbalance, or bias, of the VOR was defined as the ratio of mean rightward to leftward slow-phase eye velocities. The difference in rightward and leftward slow-phase velocities shown in Figure 1 was $0.47 \mathrm{deg} / \mathrm{sec}$. Mean velocities for the VOR at three test frequencies $(0.125,0.25$, and $0.45 \mathrm{~Hz})$ and their $R / L$ ratios are shown in Table 2 for all 4 subjects. The results are presented for the first two 16-sec periods of the recording in order to illustrate the stability of the baseline response.

\section{Effects of Short-Term Exposure}

\section{Circular Vection in Darkness}

Visual stimulation. During adaptation to purely visual motion, observers were seated on a stationary chair inside the optokinetic drum, which was rotated leftward about the subject at a velocity of $18 \mathrm{deg} / \mathrm{sec}$. Eye movements were suppressed during visual stimulation with a head-earth-referenced fixation spot. After $1 \mathrm{~min}$ of leftward stimulus motion, the room lights were turned out and the stationary subjects were instructed to continue to look in the direction that the fixation spot had previously occupied. Immediately following adaptation, the stationary subjects reported a rightward sensation of apparent body rotation in darkness, in the direction opposite to that of the previous adapting stimulus (noninverted vection). The duration of the aftereffect is listed for each of the 4 subjects in Table 3.
Visual-vestibular stimulation. During combined stimulation, the optical flow pattern was the same as that described in the preceding section, but the subject's chair position was oscillated sinusoidally at $0.25 \mathrm{~Hz}$ about its vertical axis $\left(36^{\circ}\right.$, peak to peak). During adaptation, eye movements were suppressed by using a head-referenced fixation spot that oscillated with the subject's chair. This fixation procedure resulted in a retinal slip velocity that was continually changing from as little as zero in one phase of chair movement to a maximum of twice that of the chair alone when the chair reached its peak velocity in the direction opposite to that of the drum's rotation. After $1 \mathrm{~min}$ of combined stimulation, the lights were turned off and the chair oscillation was halted. The observer was instructed to look in the straight-ahead position in darkness, as before, and to report the direction of sensed self-rotation once every $4 \mathrm{sec}$. In Table 3, the durations of these aftereffects are compared with those of aftereffects following purely visual stimulation. The comparisons reveal that there were longer aftereffects of circular vection for all 4 subjects in the combined stimulus condition than in the purely visual stimulus condition.

\section{Vestibular Induced Self-Motion Perception}

Visual stimulation. The same, purely visual adaptation condition was repeated as described above. Following 1 min of adaptation, the subject was sinusoidally oscillated at $0.25 \mathrm{~Hz}$ in darkness while he/she verbally reported the perceived velocity ratio $(R / L)$ of body rotation. The means of $R / L$ ratios were calculated from the first $32 \mathrm{sec}$ of reported self-motion in darkness, since the aftereffects decayed throughout the recording period (see Figure 3 for an example of self-motion aftereffects during the entire 64-sec recording period). Table 1 shows that, in all 4 subjects, adaptation to leftward motion of the visual field caused a reduction, or habituation, of sensitivity to perceived leftward body rotation in darkness. Although the reduced leftward sense of self-motion was the main observation, in some cases, there was also the report of an enhanced sensation of body rotation to the right.

To determine the influence of the circular vection aftereffect upon asymmetries of vestibular induced selfmotion perception, we compared the durations of both aftereffects measured in darkness. Table 3 shows that the durations of the two aftereffects were unequal. Asymmetries of vestibular induced self-motion perception lasted an average of 7.5 times longer than circular vection aftereffects in darkness.

Visual-vestibular stimulation. Table 1 shows that adaptation to combined stimulation produced changes in vestibular induced self-motion perception equivalent to that produced with the purely visual stimulus. A comparison of the durations of aftereffects of the two adaptation conditions (visual vs. visual-vestibular), shown in Table 3, reveals that asymmetries of vestibular induced self-motion perception persisted longer with the combined adaptation stimulus. The mean duration of asymmetric aftereffects 
Table 2

Baseline VOR and Fixation

\begin{tabular}{|c|c|c|c|c|c|c|c|c|c|}
\hline \multirow[b]{2}{*}{ Subject } & \multirow{2}{*}{\multicolumn{2}{|c|}{$\begin{array}{c}\text { Frequency of } \\
\text { Chair (Hz) }\end{array}$}} & & \multicolumn{6}{|c|}{ Slow-Phase Eye Velocity (Degrees/Second) } \\
\hline & & & & \multicolumn{3}{|c|}{$0-16$ Seconds } & \multicolumn{3}{|c|}{ 16-32 Seconds } \\
\hline \multicolumn{10}{|c|}{ Dark Drift Bias } \\
\hline $\begin{array}{l}\text { A.B. } \\
\text { B.B. } \\
\text { C.W. } \\
\text { C.S. }\end{array}$ & & $\begin{array}{l}0 \\
0 \\
0 \\
0\end{array}$ & & & $\begin{array}{l}.32 \mathrm{R} \\
.15 \mathrm{R} \\
.35 \mathrm{R} \\
.21 \mathrm{~L}\end{array}$ & & & $\begin{array}{l}35 \mathrm{R} \\
.07 \mathrm{R} \\
41 \mathrm{R} \\
.23 \mathrm{~L}\end{array}$ & \\
\hline \multirow[b]{2}{*}{ Subject } & \multirow{2}{*}{$\begin{array}{c}\text { Frequency of } \\
\text { Chair (Hz) }\end{array}$} & \multicolumn{4}{|c|}{ 0-16 Seconds } & \multicolumn{4}{|c|}{ 16-32 Seconds } \\
\hline & & $\mathbf{L}$ & $\mathbf{R}$ & R-L & $\mathrm{R} / \mathrm{L}$ & $\mathbf{L}$ & $\mathbf{R}$ & R-L & $\mathrm{R} / \mathrm{L}$ \\
\hline \multicolumn{10}{|c|}{ Baseline VOR } \\
\hline A.B. & $\begin{array}{l}0.125 \\
0.25 \\
0.45\end{array}$ & $\begin{array}{r}3.50 \\
5.50 \\
12.67\end{array}$ & $\begin{array}{r}3.66 \\
5.97 \\
13.43\end{array}$ & $\begin{array}{l}0.16 \\
0.47 \\
0.76\end{array}$ & $\begin{array}{l}1.05 \\
1.09 \\
1.06\end{array}$ & $\begin{array}{r}3.43 \\
5.83 \\
12.70\end{array}$ & $\begin{array}{r}3.70 \\
6.19 \\
13.73\end{array}$ & $\begin{array}{l}0.27 \\
0.36 \\
1.03\end{array}$ & $\begin{array}{l}1.08 \\
1.06 \\
1.08\end{array}$ \\
\hline B.B. & $\begin{array}{l}0.125 \\
0.25 \\
0.45\end{array}$ & $\begin{array}{l}2.64 \\
4.89 \\
7.40\end{array}$ & $\begin{array}{l}2.27 \\
4.30 \\
5.40\end{array}$ & $\begin{array}{l}-0.37 \\
-0.59 \\
-2.00\end{array}$ & $\begin{array}{l}0.86 \\
0.88 \\
0.73\end{array}$ & $\begin{array}{l}2.66 \\
5.00 \\
6.50\end{array}$ & $\begin{array}{l}2.25 \\
4.91 \\
5.30\end{array}$ & $\begin{array}{l}-0.39 \\
-0.09 \\
-1.20\end{array}$ & $\begin{array}{l}0.85 \\
0.98 \\
0.82\end{array}$ \\
\hline C.W. & $\begin{array}{l}0.125 \\
0.25 \\
0.45\end{array}$ & $\begin{array}{l}2.30 \\
5.75 \\
9.68\end{array}$ & $\begin{array}{r}3.25 \\
9.88 \\
15.92\end{array}$ & $\begin{array}{l}0.98 \\
4.13 \\
6.14\end{array}$ & $\begin{array}{l}1.41 \\
1.72 \\
1.63\end{array}$ & $\begin{array}{r}2.20 \\
5.50 \\
10.45\end{array}$ & $\begin{array}{r}3.40 \\
9.63 \\
25.00\end{array}$ & $\begin{array}{r}1.20 \\
4.13 \\
14.55\end{array}$ & $\begin{array}{l}1.55 \\
1.75 \\
2.39\end{array}$ \\
\hline C.S. & $\begin{array}{l}0.125 \\
0.25 \\
0.45\end{array}$ & $\begin{array}{r}3.87 \\
6.83 \\
13.08\end{array}$ & $\begin{array}{r}4.39 \\
9.33 \\
16.15\end{array}$ & $\begin{array}{l}0.52 \\
2.50 \\
3.07\end{array}$ & $\begin{array}{l}1.14 \\
1.37 \\
1.23\end{array}$ & $\begin{array}{r}4.34 \\
8.77 \\
13.15\end{array}$ & $\begin{array}{r}6.18 \\
10.77 \\
17.00\end{array}$ & $\begin{array}{l}2.84 \\
2.00 \\
3.85\end{array}$ & $\begin{array}{l}1.42 \\
1.23 \\
1.29\end{array}$ \\
\hline
\end{tabular}

Note-Mean slow-phase velocity of preadapted (baseline) records of the VOR in response to three sinusoidal test frequencies $(0.125,0.25$, and $0.45 \mathrm{~Hz})$ as well as the velocity of fixational drifts in darkness listed for all 4 observers. Differences and ratios of rightward and leftward slow-phase components of the VOR are also shown. Means were computed from the first and last $16 \mathrm{sec}$ of a 32-sec recording in order to reveal any possible decays or time-related changes of the aftereffect during the recording period.

of visual-vestibular stimulation was $22 \mathrm{sec}$ longer than that of the self-motion asymmetries following adaptation to purely visual stimulation. Similarly, the mean duration of circular vection aftereffects following adaptation to the combined stimulus was $3 \mathrm{sec}$ longer than the mean duration of circular vection aftereffects of the purely visual stimulus.

\section{Fixation Afternystagmus}

Visual stimulation. After adaptation to a moving pattern, an afternystagmus occurred during attempted steady fixation in darkness; this had a leftward slow phase in the same direction as the preceding visual field motion (motion afternystagmus; MAN) (Brandt et al., 1974; Schor \& Westall, 1984). We use the term "motion afternystagmus" rather than "optokinetic afternystagmus" to emphasize that optokinetic nystagmus (OKN) was suppressed during the adaptation period. The slow-phase velocity of MAN was quantified every $0.5 \mathrm{sec}$, and means were computed from the first $32 \mathrm{sec}$ of the recording. The time taken for drift bias of MAN to decline to the baseline dark drift velocity was noted. A comparison of Tables 2 and 4 reveals that $1 \mathrm{~min}$ of adaptation to purely leftward motion of the visual field resulted in an increase in leftward fixational drifts (MAN) in darkness for all 4 subjects.

Visual-vestibular stimulation. Tables 3 and 4 illustrate that both the duration and velocity, respectively, of the leftward drift component of afternystagmus were greater following adaptation to the combined visualvestibular stimulus than to the purely visual stimulus.

\section{Horizontal Symmetry of the VOR}

Visual stimulation. Figure 2 illustrates the VOR stimulated in darkness by $0.25-\mathrm{Hz}$ sinusoidal rotation, after a 1-min adaptation to a purely leftward rotation of the visual

Table 3

Duration of Modified Fixation Drift, VOR, Vection, and Self-Motion Perception

\begin{tabular}{llcccl}
\hline & & \multicolumn{3}{c}{ Duration of Aftereffect (Seconds) } \\
\cline { 3 - 6 } Subject & Stimulus & Self-Motion & & & \\
\hline A.B. & Vis & 64 & 12 & 14 & 64 \\
& Vis-vestib & 80 & 14 & 19 & 76.5 \\
B.B. & Vis & 70 & 11 & 10 & 60 \\
& Vis-vestib & 74 & 10 & 15 & 70.5 \\
C.W. & Vis & 73 & 4 & 8 & 54 \\
& Vis-vestib & 130 & 10 & 11 & 125 \\
C.S. & Vis & 50 & 8 & 10 & 50 \\
& Vis-vestib & 60 & 13 & 13 & 56 \\
Mean & & 75.13 & 10.25 & 11.88 & 69.50 \\
\hline
\end{tabular}

Note-The durations (seconds) for MAN, the VOR, circular vection, and modified self-motion perception to return to baseline values listed following the two adaptation conditions (visual and visual plus vestibular). Clearly, the modified VOR and modified self-motion perception persist approximately five times longer than the modified fixation-drift velocity and aftereffects of circular vection. 
Table 4

Modified VOR and Fixation Nystagmus in Darkness

\begin{tabular}{lllllll} 
& & \multicolumn{5}{c}{ Eye Velocity (Degrees/Second) } \\
\cline { 5 - 8 } Subject & Stimulus & & \multicolumn{4}{c}{ VOR } \\
\cline { 5 - 8 } & Condition & MAN & L & R & R-L & R/L \\
\hline A.B. & Vis & $0.47 \mathrm{~L}$ & 6.39 & 5.28 & -1.11 & 0.83 \\
& Vis-vestib & $1.04 \mathrm{~L}$ & 8.34 & 5.84 & -2.50 & 0.70 \\
B.B. & Vis & $0.68 \mathrm{~L}$ & 5.84 & 4.20 & -1.63 & 0.72 \\
& Vis-vestib & $0.84 \mathrm{~L}$ & 6.09 & 4.26 & -1.83 & 0.70 \\
C.W. & Vis & $1.00 \mathrm{~L}$ & 6.72 & 7.72 & 1.00 & 1.15 \\
& Vis-vestib & $1.30 \mathrm{~L}$ & $\mathbf{6 . 7 9}$ & 7.71 & 0.92 & 1.13 \\
C.S. & Vis & $0.34 \mathrm{~L}$ & 7.09 & 7.04 & -0.05 & 0.99 \\
& Vis-vestib & $0.89 \mathrm{~L}$ & 6.86 & 5.67 & -1.19 & 0.83 \\
\hline
\end{tabular}

Note-Mean slow-phase velocities for rightward and leftward components of the VOR stimulated at $0.25 \mathrm{~Hz}\left(36^{\circ}\right.$ peak to peak) in darkness listed for 4 observers. Prior to measuring the VOR, the observers adapted for $1 \mathrm{~min}$ to an 18-deg/sec rotation of the visual field while they remained stationary or while they were oscillated about a vertical axis at $0.25 \mathrm{~Hz}\left(36^{\circ}\right.$ peak to peak). Fixation was head-referenced during both adaptation conditions to prevent the occurrence of optokinetic nystagmus. The mean slow-phase velocities of aftereffects in darkness were computed from the first $32 \mathrm{sec}$ in darkness, since the drift bias (MAN) decayed rapidly during this period (see Table 3 ). Differences (R-L) and ratios $(R / L)$ of slow-phase means of the VOR are also shown. The leftward bias of fixation drifts in darkness (MAN) resulting from the combined visual vestibular stimulus was greater, for all 4 subjects, than that resulting from adaptation to a visual stimulus, although two adaptation conditions resulted in similar asymmetries for the VOR. The leftward bias of R-L differences for the VOR are greater than the baseline measures shown in Table 1 for all 4 observers.

field at $18 \mathrm{deg} / \mathrm{sec}$. A comparison of the results shown in Figures 1 and 2 clearly reveals a marked alteration of the slow-phase velocity of the VOR from a preadapted rightward bias to a marked postadapted leftward bias.
Mean velocities of the first $32 \mathrm{sec}$ of the VOR and MAN are listed in Table 4 for all 4 subjects. A 32-sec interval was analyzed because MAN decays rapidly during this period. Table 4 illustrates that the velocity differences between the rightward and leftward slow-phase components of the VOR were equal to or greater than the velocities of MAN in all but one subject (C.W.), who had a marked rightward slow-phase bias of the baseline VOR. In all cases, following adaptation to a leftward rotation of the visual field, the leftward slow phase of the VOR increased and the rightward slow phase decreased from the baseline response shown in Table 2 .

The length of time it took for the slow phase of the components of MAN and the VOR to return to their baseline levels is shown in Table 3, along with other data, in rows corresponding to the "Vis" stimulus condition. The mean durations of the modified VOR are 5.85 times greater than the duration of MAN. These results confirm previous observations indicating that the VOR can be modified by a purely visual stimulus and that modification of the VOR does not require a conflict between visual and vestibular stimuli (Yee \& Baloh, 1986; Young \& Henn, 1974, 1976).

The unequal durations of MAN and the modified slow phase of the VOR indicate that the VOR was not simply modified by the linear addition of MAN. The modified VOR appears to result from a change in slow-phase gain. Gain changes were demonstrated by adapting subjects for $1 \mathrm{~min}$ to a constant $18-\mathrm{deg} / \mathrm{sec}$ angular rotation of the visual field and then measuring, in darkness, the VOR to three sinusoidal test frequencies $(0.125,0.25$, and $0.45 \mathrm{~Hz}$ ). These three test frequencies had the same $36^{\circ}$ peak-to-peak angular displacement. The R/L slow-phase

A. $B$

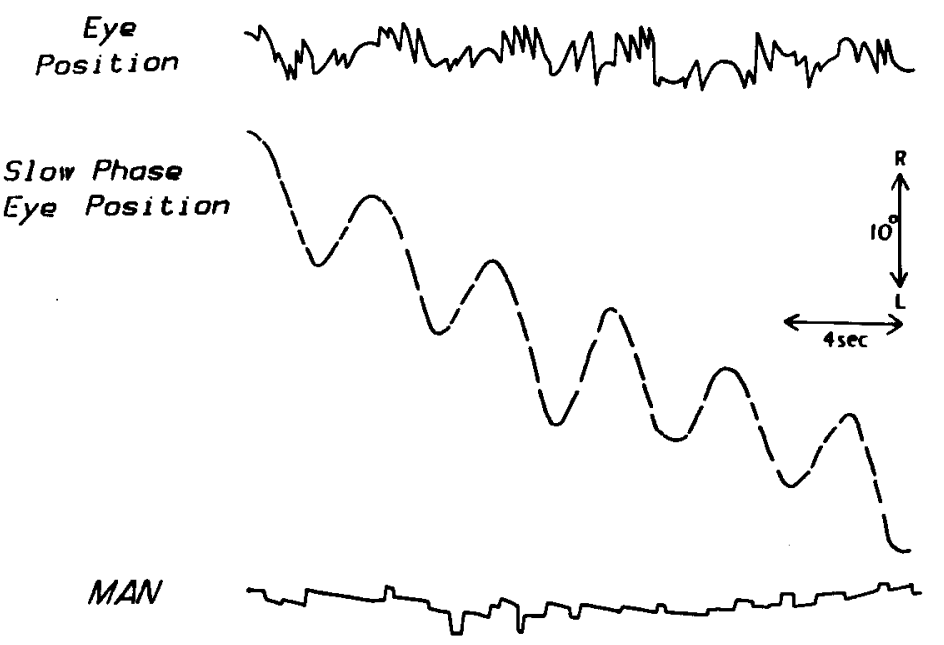

Figure 2. The VOR of the same subject and stimulus conditions as in Figure 1 (top trace) after the observer adapted for 1 min to a leftward rotation of the visual field at $18 \mathrm{deg} / \mathrm{sec}$. The cumulative slow-phase bias (middle trace) of the modified VOR is altered from rightward to leftward. Also shown are the fixational eye movements following adaptation (MAN) when the observer was stationary in darkness (bottom trace). This motion afternystagmus also has a leftward slow-phase bias. 
velocity ratio of the pre- and postadapted VOR are compared in Table 5. If the VOR was modified by the linear summation of MAN with the slow phase of the VOR, then we would expect the greatest change in the R/L slowphase ratio to occur at low stimulus frequencies. If, on the other hand, there was a slow-phase gain change of the VOR, then we would expect the $R / L$ ratio to be less dependent on test frequency. Inspection of Table 5 reveals that the ratio was, indeed, independent of test frequency, which supports the altered-gain hypothesis and rejects the summation hypothesis.

Visual-vestibular stimulation. Table 4 illustrates the mean slow-phase velocities and the R/L ratio of the VOR stimulated in darkness by $0.25-\mathrm{Hz}$ sinusoidal rotation, after 1-min adaptation to the combined stimulus. The leftward bias of the VOR (reduced $R / L$ ratio) resulting from the combined visual-vestibular stimulus was greater for all 4 subjects than were the aftereffects resulting from adaptation to a visual stimulus alone.

Directional biases of the VOR and self-motion perception, measured in darkness, are compared for 1 subject (A.B.) in Figure 3. The R/L ratio of slow-phase velocities and of perceived self-motion are plotted in 8-sec intervals for a $64-\mathrm{sec}$ duration. The ratios of the VOR and self-motion perception changed in opposite directions, inasmuch as leftward eye movements occurred during perceived rightward body rotation. The variations in magnitude of sensory and motor aftereffects during sequential 8-sec intervals were highly correlated. Correlation coefficients for all subjects ranged from -0.81 to -0.99 with a mean of -0.84 .

\section{Effects of Long-Term Exposure}

\section{Circular Vection in Darkness}

Subjects C.W. and C.S. adapted to a purely leftward rotation of the visual field $(18 \mathrm{deg} / \mathrm{sec})$ for a $15-\mathrm{min}$ period. Following adaptation, both subjects reported an inverted circular vection in darkness while they were stationary. The observers had the illusion of leftward body rotation (in the same direction as the adapting stimulus). Inverted vection lasted four times longer than the noninverted vection that followed short-term adaptation.

Table 5

VOR Frequency Responses

\begin{tabular}{lccc}
\hline & \multicolumn{3}{c}{ Test Frequencies } \\
\cline { 2 - 4 } Subject & $.125 \mathrm{~Hz}$ & $.25 \mathrm{~Hz}$ & $.45 \mathrm{~Hz}$ \\
\hline A.B. & 0.96 & 0.89 & 0.96 \\
B.B. & 0.85 & 0.70 & 0.71 \\
C.W. & 1.00 & 1.10 & 0.07 \\
C.S. & 1.00 & 1.00 & 0.98 \\
Mean & 0.95 & 0.92 & 0.93 \\
\hline
\end{tabular}

Note-The ratio of mean rightward/leftward slow-phase velocities of the VOR, stimulated at three sinusoidal test frequencies in darkness, shown after adaptation for $1 \mathrm{~min}$ to an 18-deg/sec leftward rotation of the visual field. Mean velocities were calculated from the first $32 / \mathrm{sec}$ of the VOR in darkness, during which eye movements were monitored. Clearly, the ratio of slow-phase velocities is independent of VOR test frequency, which indicates that there was a modification of slow-phase gain rather than the addition of a constant velocity error to the VOR.

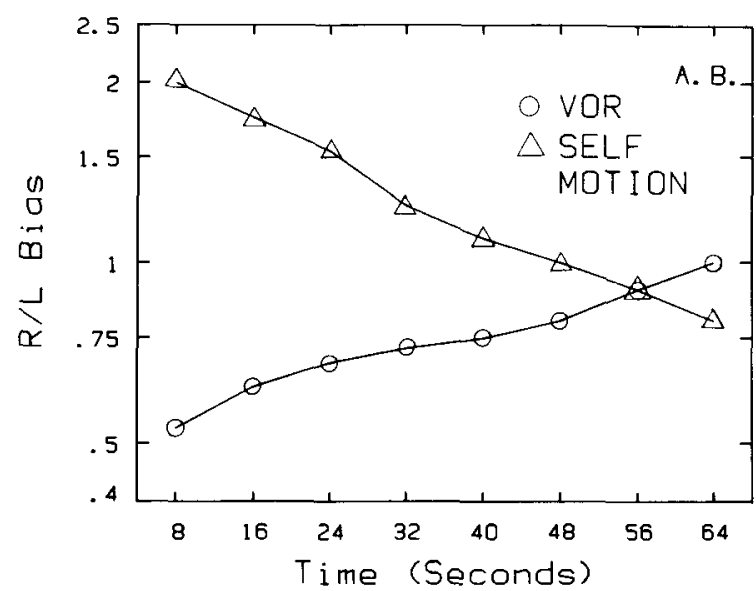

Figure 3. Directional biases plotted on log-linear coordinates in 8-sec intervals for $64 \mathrm{sec}$ as a ratio of rightward/leftward slow-phase velocities of the VOR and magnitude estimates of self-motion during sinusoidal oscillation at $0.25 \mathrm{~Hz}\left(36^{\circ}\right.$ peak to peak) in darkness after adaptation to a purely visual stimulus for $1 \mathrm{~min}$ which was an 18-deg/sec rotation of the visual field. The fluctuations of direction and magnitude of the VOR and self-motion percepts were highly correlated for all subjects and at all stimulus temporal frequencies (mean $r=-0.84$ ).

The inverted vection aftereffect had the same duration as the adapted rightward bias of the VOR shown in Figure 4.

\section{Vestibular Induced Self-Motion Perception}

Following $15 \mathrm{~min}$ of adaptation to the purely leftward rotation of the visual field, both C.W. and C.S. reported inverted asymmetries of self-motion aftereffects perceived during sinusoidal body rotation $(0.25 \mathrm{~Hz})$ in darkness. Long-term adaptation resulted in a habituation or reduction of sensitivity to rightward body rotation and, to a lesser degree, an enhanced sensitivity to leftward body rotation. These observations confirm previous findings reported by Young et al. (1973).

\section{Fixation Afternystagmus}

The bottom of Figure 4 illustrates an example of MAN recorded in darkness following long-term adaptation; this example has a slow phase that is biased in the rightward direction. The magnitude of drift bias for MAN increased for C.S. (Figure 4) and was reduced for C.W. relative to the amplitudes of their noninverted MANs following short-term exposure (derive changes in MAN by comparing Tables 4 and 6 with the baseline values of dark drift bias in Table 2).

\section{Horizontal Symmetry of the VOR}

As shown for afternystagmus, the slow-phase bias of the VOR, following long-term adaptation to leftward optical flow, was rightward (inverted), as illustrated by the cumulative slow-phase plot for C.S. near the bottom of Figure 4. The magnitude of the inverted aftereffect can be compared with the short-term aftereffect by inspection of Tables 2, 4, and 6. Inspection reveals that follow- 
ing long-term adaptation, the rightward bias $(\mathrm{R} / \mathrm{L})$ of the VOR increased from baseline by 0.75 for C.S. but by only 0.27 for C.W. In contrast, following short-term adaptation, the leftward bias of the baseline VOR increased and caused a reduction of the $R / L$ ratio of .23 for C.S. and a reduction of .62 for $C$.W.

\section{DISCUSSION}

\section{Circular Vection and Self-Motion Perception}

Previous studies of circular vection have revealed two phases (a noninverted phase and an inverted phase in directions the same as and opposite to that of the adapting stimulus, respectively) that are believed to result from two simultaneous time-dependent opponent processes (Brandt et al., 1974). In this study, we have investigated how these aftereffects interact with vestibular induced self-motion perception. Our results suggest that adaptation to optical flow produces a habituation of vestibular induced self-motion perception that is in the same direction as the optical flow. This proposed habituation may sum linearly with noninverted and inverted phases of vection aftereffects of optical flow. For example, short-term adaptation $(1 \mathrm{~min})$ results in a brief aftereffect of noninverted vection and a long duration of habituated vestibular induced self-motion

c. $s$.
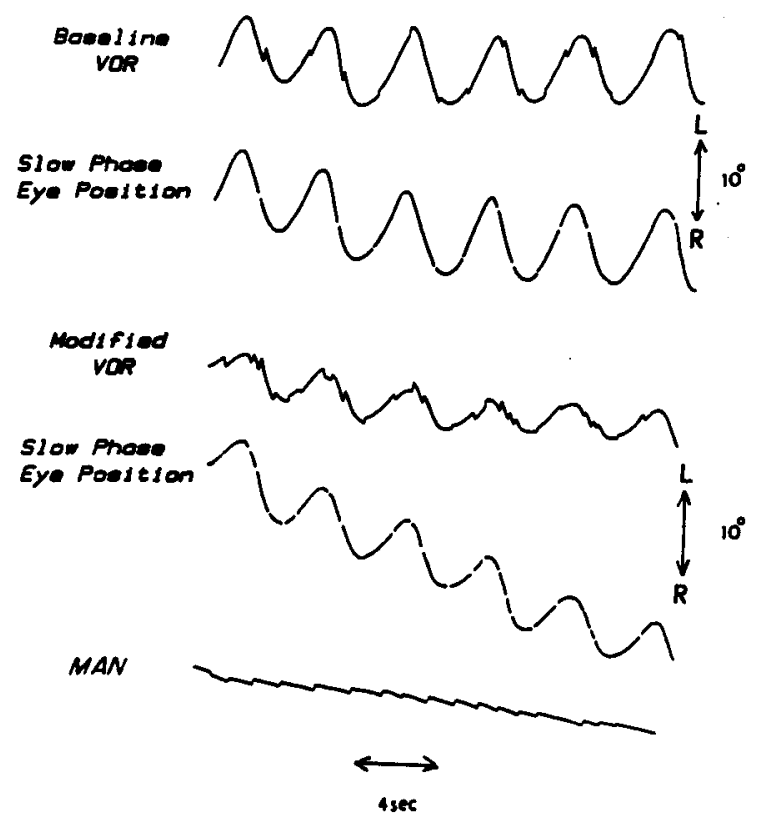

Figure 4. The baseline VOR and the VOR following adaptation for $15 \mathrm{~min}$ to leftward rotation of the visual field at $18 \mathrm{deg} / \mathrm{sec}$ are plotted in response to a $0.25-\mathrm{Hz}$ sinusoidal oscillation in darkness ( $36^{\circ}$ peak to peak). The cumulative slow-phase plots demonstrate an immediate rightward (inverted) slow-phase bias, which lasted for the entire record $(60 \mathrm{sec})$. Reductions of self-motion perception underwent the same reversal from noninverted with short-term adaptation to inverted following long-term visual adaptation to leftward motion. A marked rightward slow-phase bias of afternystagmus (inverted MAN) is also shown following the same adaptation paradigm.
Table 6

Motor Aftereffects of Long-Term Adaptation

\begin{tabular}{|c|c|c|c|c|c|c|c|c|}
\hline \multirow[b]{3}{*}{ Subject } & \multicolumn{4}{|c|}{ 0-16 Seconds } & \multicolumn{4}{|c|}{ 16-32 Seconds } \\
\hline & \multirow{2}{*}{$\frac{\overline{\text { MAN }}}{\text { Mean }}$} & \multicolumn{3}{|c|}{ VOR } & \multirow{2}{*}{$\frac{\text { MAN }}{\text { Mean }}$} & \multicolumn{3}{|c|}{ VOR } \\
\hline & & L & $\mathbf{R}$ & $\mathbf{R} / \mathbf{L}$ & & $\mathbf{L}$ & $\mathbf{R}$ & $\mathrm{R} / \mathrm{L}$ \\
\hline $\begin{array}{l}\text { C.W. } \\
\text { C.S. }\end{array}$ & $\begin{array}{l}1.12 \mathrm{R} \\
0.57 \mathrm{R}\end{array}$ & $\begin{array}{l}5.77 \\
2.81 \\
\end{array}$ & $\begin{array}{r}11.49 \\
6.94 \\
\end{array}$ & $\begin{array}{l}1.99 \\
2.47 \\
\end{array}$ & $\begin{array}{l}1.25 \mathrm{R} \\
0.51 \mathrm{R}\end{array}$ & $\begin{array}{l}9.05 \\
2.87\end{array}$ & $\begin{array}{r}16.01 \\
5.68\end{array}$ & $\begin{array}{l}1.77 \\
1.98 \\
\end{array}$ \\
\hline
\end{tabular}

Note-Values are in degrees/second. Means for slow-phase velocity, computed for 2 observers over a 32-sec period, shown for leftward and rightward components of baseline and modified VOR in darkness, following $15 \mathrm{~min}$ of adaptation to a leftward rotation of the visual field at $18 \mathrm{deg} / \mathrm{sec}$. Following adaptation, the slow phase of the VOR was biased in the rightward direction relative to baseline values in Table 1. Also shown is the mean rightward drift velocity of a negative MAN following adaptation to the same stimulus.

perception. Both of these aftereffects bias self-motion perception in the direction opposite to that of the previous adapting stimulus. The difference in duration of these two aftereffects suggests that noninverted vection contributes little to the changes in vestibular induced self-motion perception following short-term adaptation.

Long-term (15 $\mathrm{min}$ ) adaptation to optical flow results in an inversion of the short-term aftereffect described above. This inversion could have resulted from the summation of a long-term inverted vection aftereffect with the noninverted habituation of vestibular sensitivity described above. The bias of the noninverted habituation of vestibular sensation may be cancelled or overshadowed by a stronger opposing bias of inverted vection aftereffects which would result in a net bias of self-motion perception in the same direction as that of the previous adapting stimulus. The magnitude and direction of the long-term aftereffect would depend upon the relative strengths of the opponent aftereffects. Accordingly, the differences in the magnitudes of aftereffects with long-term adaptation for C.S. and C.W. may have resulted from differences in the magnitudes of their inverted vection and habituated vestibular sensations.

\section{The VOR and Motion Afternystagmus}

The results clearly illustrate that the slow-phase velocity of the VOR can be modified following adaptation to either purely visual motion or a combination of visualvestibular stimulation. The two adapting stimuli caused unequal changes in the $R / L$ ratio for both the VOR and motion afternystagmus. The combined visual-vestibular adaptation stimulus resulted in a greater increase in the leftward dark drift velocity and a greater decrease in the $\mathrm{R} / \mathrm{L}$ ratio of the VOR than did the purely visual motion stimulus. The combined visual-vestibular adaptation stimulus also resulted in longer durations of aftereffects for the leftward bias of both the VOR and dark drift velocity than did the purely visual adaptation stimulus. One of the main differences between the two adaptation conditions was that retinal slip reached higher velocities during the combined stimulus motion than during pure visual motion. However, Koenig and Dichgans (1981) observed that the amplitude of optokinetic afternystagmus (OKAN) 
is largely independent of pattern speed, which suggests that vestibular stimulation, rather than altered pattern speed, during adaptation contributed to the increased leftward slow-phase velocity of the VOR and afternystagmus.

The contribution of motion afternystagmus to asymmetries of the VOR varied with duration of adaptation to the moving textured visual field. Motion afternystagmus persisted for only 6-20 sec after short-term adaptation, whereas the imbalance of the VOR persisted for over $1 \mathrm{~min}$. Consequently, motion afternystagmus contributed little to the imbalance of the VOR caused by short-term visual adaptation. The asymmetry of the VOR induced by short-term adaptation appears to result from a change in slow-phase gain. This interpretation is confirmed by the invariance of the asymmetric $R / L$ ratio of the VOR stimulated at different temporal frequencies. If the changes of the VOR had been caused by the linear summation of afternystagmus with the VOR, then changes of the $R / L$ ratio would have been larger at low frequencies than at high frequencies.

In contrast to the aftereffects of short-term adaptation, long-term visual adaptation $(15 \mathrm{~min})$ resulted in a prolonged inversion of MAN, whose slow phase was in a direction opposite to that of the adapting stimulus. This inverted afternystagmus was also observed by Brandt et al. (1974) and Young and Henn (1976) after similar periods of motion adaptation. The duration of this inverted MAN was similar to the duration of the modified slowphase velocity of the VOR, which suggests that MAN contributes more to the apparent changes in slow-phase gain of the VOR following long-term than following short-term visual adaptation.

The results of this and other investigations demonstrate that there are rapid adjustments of the VOR that do not require the presence of a conflict between visual and vestibular stimuli, but that the presence of a conflict results in aftereffects that are greater than those obtained with a purely visual stimulus. Retinal image motion alone is sufficient to modify the slow-phase gain of the VOR (Yee \& Baloh, 1986; Young \& Henn, 1974). Since the VOR receives no direct feedback, it is important for it to be modified by visual feedback (Miles \& Lisberger, 1981). The VOR adapts too slowly to make rapid corrections for retinal velocity errors during head movements. Apparently, the VOR is calibrated by retinal image slip or motion, whether it is produced by optokinetic stimuli or by inaccurate vestibular compensation for head and body movement. Visual adaptation to motion could help to calibrate the VOR in order to maintain stability of the retinal image of a moving visual field during head rotation. For example, under conditions of constant optical flow, such as while riding in a car, the slow phase of the VOR needs to be greater when the head rotates in the direction opposite to that of the optical flow than when it rotates in the same direction. Adaptation to the moving visual field could prepare the VOR in advance for accurate compensation of occasional head rotation.

\section{REFERENCES}

Brandt, Th., Dichgans, J., \& Buchele, W. (1974). Motion habituation: Inverted self-motion perception and optokinetic after nystagmus. Experimental Brain Research, 21, 337-352.

Brandt, Th., Dichgans, J., \& Koenig, E. (1973). Differential effects of central versus peripheral vision on egocentric and exocentric motion perception. Experimental Brain Research, 16, 476-491.

Collewijn, H., Martins, A. J., \& Steinman, R. M. (1983). Compensatory eye movements during active and passive head movements: Fast adaptation to changes in visual magnification. Journal of Physiology (London), 340, 259-286.

DichgaNs, J., \& BRANDT, TH. (1972). Visual-vestibular interaction and motion perception. In J. Dichgans \& E. Bizzi (Eds.), Cerebral control of eye movements and motion perception (pp. 327-338). BaselNew York: S. Karger.

Fischer, M. H., \& Kornmuller, A. E. (1930). Optokinetisch ausgeloste Bewegungswahrnehmungen und optokinetischer Nystagmus. Journal für Psychologie und Neurologie, 41, 273-308.

Gonshor, A., \& Melvill Jones, G. (1976). Short-term adaptive changes in the human vestibulo-ocular reflex arc. Journal of Physiology (London), 256, 361-379.

Henn, V., Cohen, B., \& Young, L. (Eds.) (1980). Visual-vestibular interaction in motion perception and the generation of nystagmus (Neurosciences Research Program Bulletin, Vol. 18, No. 4). Cambridge, MA: MIT Press.

KoENIG, E., \& Dichgans, J. (1981). Aftereffects of vestibular and optokinetic stimulation and their interaction. In B. Cohn (Ed.), Vestibular and oculomotor physiology: International Meeting of the Barany Society. Annals of the New York Academy of Sciences, 374, 434-445.

Lisberger, S. G., Miles, F. A., Optican, L. M., \& Eighmy, B. B. (1981). Optokinetic responses in monkey: Underlying mechanisms and their sensitivity to long-term adaptive change in the vestibular reflex. Journal of Neurophysiology, 45, 869-890.

Miles, F. A., \& Eighmy, B. B. (1980). Long-term adaptive changes in primate vestibulo-ocular reflex. I. Behavioral observations. Journal of Neurophysiology, 43, 1406-1425.

Miles, F. A., \& LISBERGER, S. G. (1981). Plasticity in the vestibuloocular reflex: A new hypothesis. Annual Review of Neuroscience, 4, 273-299.

Schor, C. M., Lakshminarayanan, L., \& Narayan, V. (1984). Optokinetic and vection responses to apparent motion in man. Vision Research, 24, 1181-1187.

SCHOR, C. M., \& WESTALL, C. A. (1984). Visual and vestibular sources of fixation instability in amblyopia. Investigative Ophthalmology \& Visual Science, 25, 729-738.

Westall, C. A., \& Schor, C. M. (1985). Adaptation of the vestibuloocular reflex in amblyopia. Investigative Ophthalmology \& Visual Science, 26, 1724-1730.

YEE, R., \& BALOH, R. (1986). Adaptation of the VOR after short periods of optokinetic stimulation in man. In D. Zee \& E. Keller (Eds.), Adaptive processes in visual and oculomotor systems. New York: Pergamon Press.

Young, L. R., Dichgans, J., Murphy, R., \& Brandt, Th. (1973). Interaction of optokinetic and vestibular stimuli in motion perception. Acta Oto-laryngologica, 76, 24-31.

Young, L. R., \& HENN, V. S. (1974). Selective habituation of vestibular nystagmus by visual stimulation. Acta Oto-laryngologica, 77, 159-166.

Young, L. R., \& HeNn, V. S. (1976). Selective habituation of vestibular nystagmus by visual stimulation in alert monkey. Acta Otolaryngologica, 82, 165-171.

(Manuscript received December 23, 1985; revision accepted for publication April 30, 1986.) 